\title{
Soldiers or Bureaucrats? Conflict and the Military's Role in Policy- Making
}

\author{
Gabriel J. Leon* \\ London School of Economics and STICERD
}

June 2009

The Suntory Centre

Suntory and Toyota International Centres for Economics and Related Disciplines

London School of Economics and Political Science Houghton Street

London WC2A 2AE

EOPP 12

Tel: (020) 79556674

\footnotetext{
* Address: STICERD, LSE, Houghton Street, London WC2A 2AE, UK. Email: g.j.leon@lse.ac.uk. Website: http://personal.lse.ac.uk/leongj. I wish to thank Tim Besley, Christopher Coker, Karen Croxson, Christopher Dandeker, Anke Hoeffler, Rafael Hortala-Vallve, Clare Leaver, Sebastian Linnemayr, Rocco Macchiavello, Sharun Mukand, Gerard Padro-i-Miquel, Torsten Persson, Francis Teal, Jonathan Temple, Harold Trinkunas and Pedro Vicente for their help and comments. I kindly acknowledge the financial support of the ESRC.
} 


\begin{abstract}
One of the most striking institutional features of many less developed countries is that their militaries are closely involved in policy-making, potentially having a large impact on economic outcomes. This paper examines the role of the military in setting policy. For this purpose it develops one of the first models of the military, where its political involvement can take two forms: direct when the military runs the government, and indirect when it influences policy without governing directly. We focus on civilian regimes and find that war decreases the payoff to the military from both forms of involvement, but also makes staging successful coups easier. In equilibrium, an increase in the likelihood of war makes indirect involvement less likely; its impact on coups, which are aimed at establishing direct control, is nonmonotonic. We show empirical evidence for this non-monotonic relationship, with coups being least likely for low and high probabilities of war.
\end{abstract}

JEL Codes: O38, O17, H11, H56, D72.

Keywords: institutions, conflict, political economy, military, war, coups. 
This series is published by the Economic Organisation and Public Policy Programme (EOPP) located within the Suntory and Toyota International Centres for Economics and Related Disciplines (STICERD) at the London School of Economics and Political Science. This new series is an amalgamation of the Development Economics Discussion Papers and the Political Economy and Public Policy Discussion Papers. The programme was established in October 1998 as a successor to the Development Economics Research Programme. The work of the programme is mainly in the fields of development economics, public economics and political economy. It is directed by Maitreesh Ghatak. Oriana Bandiera, Robin Burgess, and Andrea Prat serve as codirectors, and associated faculty consist of Timothy Besley, Jean-Paul Faguet, Henrik Kleven, Valentino Larcinese, Gerard Padro i Miquel, Torsten Persson, Nicholas Stern, and Daniel M. Sturm. Further details about the programme and its work can be viewed on our web site at http://sticerd.lse.ac.uk/research/eopp.

Our Discussion Paper series is available to download at:

http://sticerd.lse.ac.uk/_new/publications/series.asp?prog=EOPP

For any other information relating to this series please contact Leila Alberici on:

Telephone: UK+20 79556674

Fax: $\quad$ UK+20 $\quad$ : $\quad$ (a556951

Email: $\quad$ l.alberici @lse.ac.uk

(c) The author. All rights reserved. Short sections of text, not to exceed two paragraphs, may be quoted without explicit permission provided that full credit, including (C) notice, is given to the source. 


\section{Introduction}

A large literature in economics has emphasized the importance of institutions in determining economic outcomes (e.g. North and Thomas, 1973; North, 1981; Acemoglu, Johnson and Robinson, 2001) and shown that political institutions may partly account for the differences in economic performance seen across countries (e.g. Persson and Tabellini, 2003; Besley and Kudamatsu, 2008). Surprisingly, this literature has largely neglected the role of the military. This omission is problematic: not only is the military central in bringing about institutional change, but its degree of involvement in the policy-setting process is one of the key dimensions along which political institutions differ across countries. Without an understanding of what determines the military's political involvement, it is difficult to develop a clear picture of how institutions affect economic outcomes.

In this paper we present one of the first formal models of the military and use it to address two questions: what determines the military's role in (non-military) policy-making? When does the military assume a direct role by taking control of the government, and when does it have an indirect role by influencing policy without governing directly? We suggest that both roles have costs and benefits that depend on a number of factors; we emphasize one that is of special relevance in the case of the military: the probability of war. ${ }^{1}$ We characterize the patterns of military involvement across countries as a function of the conflict environment, derive the empirical prediction that there is a non-monotonic relationship between the likelihood of wars and coups, and show empirical evidence that supports this prediction.

Our model considers a dynamic environment where two players, a general (representing the military) and a politician (representing the government) derive utility from the wars won by the country and their own involvement in policy. In every period the general can focus on defense or policy, capturing the trade-off between preparing for war and non-military policy-making. ${ }^{2}$

\footnotetext{
${ }^{1}$ Social scientists have long emphasized the importance of war in determining social, political and economic institutions. For example, Howard (1976) explains that feudalism arose out of the need to finance the cost of knights' armour and horses. More recently, Tilly (1990) and Besley and Persson (2008a,bc, 2009) have argued that war created the conditions necessary for the development of state capacity in Western Europe.

${ }^{2}$ This trade-off is frequently discussed in the literature; for example, see Nunn (1976, p.186) and Huntington
} 
Most of our analysis focuses on civilian regimes where a politician is in office. ${ }^{3}$ The politician must decide whether to task the general with defense, in which case wars may be won but the general can stage coups; or with policy, in which case wars are lost but coups are avoided. If tasked with defense, the general must decide whether to stage a coup. Naturally, the optimal choices will depend on the parameters of the model, and in particular on the likelihood of war.

In equilibrium, a high likelihood of war makes indirect involvement less likely. The reason is that involvement in policy causes the general to lose wars, and this is more costly when war is likely. So the likelihood of war reduces the relative value the general assigns to policy. In addition, war also increases the cost to the politician of tasking the general with policy, and so she is less likely to do so. Both of these effects operate in the same direction, making indirect control less likely. The effect war has on the general's decision to stage coups and try to establish direct control over policy is more complex. In addition to the forces just outlined, war induces the politician to make the military stronger, and this makes it is easier for the general to stage a successful coup. ${ }^{4}$ So although direct control is less attractive to the general when war is likely (because he would rather focus on defense), it is less costly to establish.

Combining these forces, the model predicts a non-monotonic relationship between the likelihood of war and coups in civilian regimes, with coups least likely when war is unlikely (because the politician tasks the general with policy and coups cannot succeed) and very likely (because the politician tasks the general with defense but the general does not want to stage coups). To understand the underlying logic, suppose that war is unlikely. The general will want to focus on policy; if made to focus on defense, he will stage a coup so that he can change his focus in the future. To avoid the coup, the politician tasks the general with policy. The cost of doing this, namely reducing the general's ability to fight wars, is small because wars are infrequent. On the other hand, when war is very likely the general does not wish to stage coups; gaining control over policy is costly because it involves undermining his ability to fight wars. Coups are unlikely (1957, p.70-72). We discuss this in more detail when we present the model.

${ }^{3}$ More specifically, we focus on regimes where the incumbent is not a military officer. The data analyzed in Section 6 shows that the vast majority of governments, including most autocracies, are led by civilians.

${ }^{4}$ This is because a military tasked with defense will be prepared for all types of military action, including coups. 
as a result, even when the military is focused on defense and coups are likely to succeed. Coups are most likely at intermediate likelihoods of war, when it is possible for the general to want to stage coups, but for the politician to find it too costly to have him focus on policy.

These results allow us to rationalize the patterns of military political involvement across countries as a function of the conflict environment, and in the process reconcile two conflicting views on this issue. The first is known as the garrison state view and suggests that war leads to a politically involved military; the second, the institutional view, asserts that war reduces the military's involvement in politics and causes it to become focused on defense. ${ }^{5}$ Our result that war reduces indirect control over policy is consistent with the institutional view. When we instead look at the military's attempts to establish direct control, the institutional view holds only when war is frequent. For low levels of conflict an increase in the frequency of war results in more coups and the possibility of a transition to a military regime, which is consistent with the garrison state view.

Our results are robust to allowing war to be endogenous: a country can be attacked or it can choose to attack its neighbor. We find that a country with a military focused on defense is more likely to use its strength to start a war in times of peace. In addition, an increase in the threat environment faced by the country (in the form of a higher probability of being attacked) makes it more likely that the country will have a strong military, which then makes it more likely that the country will use it in times of peace, giving rise to a spiral of conflict. These results are related to some of the findings in the strategic arms buildup literature (see Chassang and Padro-i-Miquel, 2008; Jackson and Morelli, 2008).

Our model represents an alternative to the formulation in Feaver (2003), who models the U.S. military as an agent of the government and examines when the military shirks and disobeys the executive's orders. Acemoglu, Ticchi and Vindigni (2009) follow a similar approach with a model where the military can act as an agent of the elite; they use the model to provide micro-

\footnotetext{
${ }^{5}$ The garrison state view is associated with Harold Laswell $(1937,1941)$, who was concerned with the increasing militarization of society in Japan and Germany before the Second World War; the second view is due to Stanislav Andreski $(1968,1980)$ and has been used to explain civilian control of the U.S. and Soviet militaries during the Cold War (Desch, 1999).
} 
foundations for the role played by the military in the literature on political transitions (Acemoglu and Robinson, 2001, 2005). ${ }^{6}$ Their model also predicts when the military will disobey the elite, overthrow it, and establish a military dictatorship. Our model differs in that it is focused on the military's role in policy-making, rather than on transitions. Our military is an independent political player with preferences over policy, and we analyze when and how those preferences are reflected in the policy implementation process. Finally, we emphasize the importance of conflict and the military's defense role, which allows us to derive and test an empirical prediction. ${ }^{7}$

In the second part of the paper we test the model's prediction of a non-monotonic relationship between the likelihood of war and coups in civilian regimes. We use two specifications that capture this non-monotonicity in a simple way: one where the probability of a coup is a quadratic function of the likelihood of war, and one where the coefficient on the war variable is allowed to vary with the value of that variable. We proxy for the likelihood of war in a country with the fraction of years between 1965 and 1999 in which the country was at war, and similarly for coups. We use annual data on wars from the PRIO/Uppsala Armed Conflict dataset, version 4 (Gleditsch et al. 2002, PRIO 2006), while the annual data on coups comes primarily from Belkin-Schofer (2003). We find the predicted non-monotonic relationship to be present in both specifications. As a check we compute the war and coup frequencies over five year intervals, which allows us to exploit the time dimension of our data and introduce country and time fixed effects. The results of this panel analysis are similar to those of the cross-country regressions. Overall, the empirical results provide strong evidence that the relationship between the likelihood of war and coups is indeed non-monotonic.

Our contribution to the empirical literature on the causes of coups lies in being the first to establish a relationship between the likelihood of war and coups. An important related paper is Londregan and Poole (1990), who find that income per capita, economic growth and the

\footnotetext{
${ }^{6}$ Leon (2007) considers a similar relationship between a government and its military, but from an empirical perspective. Related studies of the military, but focused on different issues, include Finer (1962), Nordlinger (1977) and Leon (2006).

${ }^{7}$ Besley and Robinson (2007) consider a military with preferences over policy. Unlike them, we emphasize the military's role in fighting wars, how this determines its ability to stage coups, and how the conflict environment affects the military's role in policy.
} 
incidence of coups in the recent past are important determinants of coups d'etat. More recently, Collier and Hoeffler (2007) argue that African militaries run protection rackets in which funding is extracted in exchange for not staging coups, and find evidence in support of this argument. Leon (2007) shows evidence consistent with the proposition that a country is most likely to face a coup when its military spending is at historically low levels.

The rest of the paper proceeds as follows: in Section 2 we describe our model of the military, while in Section 3 we derive and discuss the equilibria. In Section 4 we consider the role of war, while in Section 5 we allow war to be endogenous. In Section 6 we present empirical evidence that supports the model's main testable prediction. Section 7 concludes.

\section{A Model of the Military}

We consider an infinitely repeated game between two players, a politician (who represents all civilians) and a general (who heads the military). There are two political regimes, $r_{t} \in\{P, G\}$, which differ in the identity of the incumbent: in a civilian regime $P$ the politician is the incumbent, while in a military regime $G$ the general is the incumbent. In each period the incumbent decides whether the military is focused on defense $\left(\tau_{t}=1\right)$ or (non-military) policy $\left(\tau_{t}=0\right)$, where policy refers to all non-military activities in which the general may be involved, from running immigration and security at airports to building roads, distributing food and running banks. The trade-off between military and non-military activities is frequently discussed in the literature; Nunn (1976), for example, observes that "[n]othing is worse for military professional development than political involvement" (p.186). Huntington (1957) makes a similar argument and states that "specialized competence acquired by professional training and experience is necessary for decision and action" (p.71), and that such competence is negatively affected by involvement in politics (p.70-72). 


\subsection{Wars and Coups}

In period $t$ the nation faces a war with probability $\mu$, where $\omega_{t}=1$ if there is a war and $\omega_{t}=0$ otherwise. ${ }^{8}$ This could be any type of war, including international and civil wars, in which the politician and the general are on the same side. The probability that a war is won is given by

$$
f\left(\tau_{t}\right)=\left\{\begin{array}{lll}
\sigma & \text { if } & \tau_{t}=1 \\
0 & \text { if } & \tau_{t}=0
\end{array}\right\}
$$

where $\sigma$ measures military capability. This capability is useful for fighting wars only if the military is tasked with defense. Winning a war generates an ego-rent of $E$ for both the politician and the general; we assume that a lost war results in a payoff of $0 .{ }^{9}$

In a civilian regime, after uncertainty about the war is resolved, the general can stage a coup; let $c_{t}=1$ if he stages a coup and $c_{t}=0$ otherwise. When $\tau_{t}=1$ a coup's probability of success equals $\sigma \rho$, where $\rho$ captures exogenous factors that impact on how military capability $\sigma$ translates into a coup's probability of success. If $\rho$ is small, coups rarely succeed, even when the military has high capability $\sigma$; if $\rho$ is large, coups succeed often, even if capability $\sigma$ is low. We assume that $\sigma \rho \leq 1$, and write a coup's probability of success as follows:

$$
f^{c}\left(\tau_{t}\right)=\rho f\left(\tau_{t}\right)
$$

which captures the fact that military capability can be used to fight wars but also to stage successful coups. A military that is well prepared for war should be able to stage coups with ease: it can take the strength that was developed to fight an enemy and use it against its own government.

If the coup fails the civilian regime continues; the general is sacked and receives 0 forever after, and a new general takes his place. A successful coup, on the other hand, results in a move to a military regime; the politician is removed, the general becomes the next period incumbent,

\footnotetext{
${ }^{8}$ In Section 5 we allow the probability of war to be endogenous.

${ }^{9}$ Assuming that there is a cost $D$ to losing a war does not affect our qualitative results.
} 
and a new general and a new politician take their places. ${ }^{10}$ For simplicity, we assume that the politician cannot stage a coup to remove a general, so that military regimes are absorbing.

\subsection{Actions and Payoffs}

In a civilian regime the politician decides the military's focus; in a military regime she makes no decision. She seeks to maximize the discounted sum of her instantaneous utility

$$
\sum_{j=0}^{\infty} \beta^{j} u_{t+j}^{p}\left(\omega_{t+j} ; r_{t+j}\right)
$$

where $\beta<1$ and the instantaneous utilities are given by

$$
\begin{aligned}
& u_{t}^{p}\left(\omega_{t}=1 ; r_{t}\right)=f\left(\tau_{t}\left(r_{t}\right)\right) E+\gamma \\
& u_{t}^{p}\left(\omega_{t}=0 ; r_{t}\right)=\gamma
\end{aligned}
$$

when she is in office; she receives a per period payoff of 0 when out of office. Here $f\left(\tau_{t}\left(r_{t}\right)\right) E$ is the expected value of fighting a war, while $\gamma$ is a payoff for every period she is in office. We interpret this as an ego-rent derived from policy-making. Notice that a smaller value of $\gamma$ implies that a relatively greater weight is placed on war. Finally, coups only affect the politician's future payoffs, and do so by impacting on the identity of the future incumbent.

In a civilian regime the general must decide whether to stage a coup; in a military regime, he needs to decide the military's task. We define the general's payoff as follows:

$$
\sum_{j=0}^{\infty} \beta^{j} u_{t+j}^{g}\left(\omega_{t+j} ; r_{t+j}\right) .
$$

\footnotetext{
${ }^{10}$ We can think that there is an infinite pool of identical soldiers from which new generals are randomly drawn, and an infinite pool of identical civilians from which new politicians are randomly chosen.
} 
The instantaneous utilities are given by

$$
\begin{aligned}
u_{t}^{g}\left(\omega=1 ; r_{t}\right) & =f\left(\tau_{t}\left(r_{t}\right)\right) P+\left(1-\tau_{t}\left(r_{t}\right)\right) \delta \\
u_{t}^{g}\left(\omega=0 ; r_{t}\right) & =\left(1-\tau_{t}\left(r_{t}\right)\right) \delta
\end{aligned}
$$

when he is in office as either head of the military or as the incumbent, and he receives a payoff of 0 when out of office. Here $\delta$ is the ego-rent the general receives when the military is tasked with policy. Coups only affect the general's future instantaneous payoffs by impacting on the identity of the future incumbent. He receives a per period payoff of 0 when out of office.

Notice that the expected value of fighting wars is the same for the politician and the general, so that war produces a common benefit. Policy-making, on the other hand, generates only a private benefit given by $\delta$ or $\gamma \cdot{ }^{11}$ We assume that $\delta, \gamma<E$; this has the implication that when war is certain $(\mu=1)$ and it is won with probability one $(\sigma=1)$, then both the politician and the general place a greater weight on defense than on policy.

\subsection{Timing}

The period $t$ game proceeds as follows:

1. The incumbent is determined: if there was a successful coup in period $t-1$, the general becomes the period $t$ incumbent; otherwise the period $t-1$ incumbent remains in office.

2. The incumbent sets $\tau_{t} \in\{0,1\}$ and policy-making takes place.

3. Nature determines whether there is a war $\omega_{t} \in\{0,1\}$; it is won with probability $f\left(\tau_{t}\right)$.

4. The general decides whether to stage a coup $c_{t}\left(\tau_{t}, \omega_{t}\right) \in\{0,1\}$; it succeeds with probability $f^{c}\left(\tau_{t}\right)$.

\footnotetext{
${ }^{11}$ This is somewhat stark, but all we need is for policy-making to have a greater private benefit component than winning wars. Since defense is often taken to be one of the best examples of a public good, this is a reasonable assumption.
} 


\subsection{Equilibrium Concept}

We focus on the pure strategy Markov perfect equilibria of this game, which requires that strategies at time $t$ be conditional on the state variables and on any actions taken earlier in that period. In addition, we assume stationarity, so that the value functions do not depend on time directly.

In this game the state variables are the regime $r_{t} \in\{P, G\}$ and whether there is a war $\omega_{t}$. The strategies are given by $S^{p}\left(r_{t}, \omega_{t}\right)$ for the politician and $S^{g}\left(r_{t}, \omega_{t}\right)$ for the general, and they determine the value of the choice variables $\tau_{t}$ and $c_{t}$. A pure strategy Markov perfect equilibrium of this game is a pair of strategies $S^{p}\left(r_{t}, \omega_{t}\right)$ and $S^{g}\left(r_{t}, \omega_{t}\right)$ such that they are best responses to each other for all $r_{t}$ (i.e. in all states of the world).

\section{Equilibria}

\subsection{Value Functions}

Let $V^{p}(P)$ and $V^{p}(G)$ denote the politician's value functions, while $V^{g}(P)$ and $V^{g}(G)$ are the value functions for the general. Since we are assuming stationarity, the functions themselves are not indexed by time. In addition, because of the Markov assumption, they will only be functions of the regime type, whether there is a war, and all actions previously taken in that period. The politician's value function in a civilian regime can be written recursively:

$$
V^{p}(P)=\max _{\tau \in\{0,1\}}\left\{\begin{array}{c}
\mu\left[f(\tau) E+\gamma+\beta\left(1-c_{t}\left(\tau_{t}, \omega_{t}=1\right) f^{c}(\tau)\right) V^{p \prime}(P)\right]+ \\
(1-\mu)\left[\gamma+\beta\left(1-c_{t}\left(\tau_{t}, \omega_{t}=0\right) f^{c}(\tau)\right) V^{p \prime}(P)\right]
\end{array}\right\}
$$

where $V^{p \prime}(P)$ indicates the next period's value function. ${ }^{12}$ The first line in (2) equals the probability of war $\mu$ times the expected value in that state of the world. This expected value equals the expected value of the war, plus the expected continuation value. The continuation value equals that of a civilian regime if there is not a successful coup in the current period, and 0 otherwise.

\footnotetext{
${ }^{12}$ For simplicity we have not made explicit the dependence on the political regime. Notice that the regime impacts on these utilities only through its effect on the choice variables.
} 
The second line equals the probability that there is no war times the expected payoff in that state of the world, which equals the value of policy, plus the expected continuation value. Notice that although current payoffs depend entirely on the politician's decision, the future depends on whether the general stages a coup. This decision, in turn, can be affected by the politician's decision.

In the case of a military regime,

$$
\begin{aligned}
V^{p}(G) & =\mu\left[f(\tau) E+\gamma+\beta V^{p \prime}(G)\right]+(1-\mu)\left[\gamma+\beta V^{p \prime}(G)\right] \\
& =\mu f(\tau) E+\gamma+\beta V^{p \prime}(G)
\end{aligned}
$$

The politician makes no choices in this case, and there are no coups by assumption.

Similar logic yields the following value function for the general under civilian rule:

$$
V^{g}(P)=\mu f(\tau) E+(1-\tau) \delta+\beta \max _{c \in\{0,1\}}\left[\left(1-c_{t}\left(\tau_{t}, \omega_{t}\right)\right) V^{g^{\prime}}(P)+c_{t}\left(\tau_{t}, \omega_{t}\right) f^{c}(\tau) V^{g \prime}(G)\right]
$$

In this case the general's decision is whether to stage a coup. The first term is the expected instantaneous payoff from war, and the second is the expected instantaneous payoff from policy. The last term is the continuation value: it equals $\beta$ times the value of a civilian regime if no coup takes place; if there is a coup, it equals $\beta$ times the probability that the coup succeeds times the value of a military regime. Notice that the decision to stage a coup only affects the expected future payoffs. These are a function of the military's task $\tau$, and this is how the politician's choice can have an impact on whether coups take place.

If in a military regime,

$$
V^{g}(G)=\max _{\tau \in\{0,1\}}\left\{\mu f(\tau) E+(1-\tau) \delta+\beta V^{g \prime}(G)\right\}
$$

where the regime is an absorbing state and there are no coups.

To solve for the equilibria we use the one-stage-deviation principle, as stated in Theorem 4.2 
in Fudenberg and Tirole (1991, p.110). This theorem says that a strategy is subgame perfect if no player can gain from deviating in only one time period and after one specific history. For this theorem to hold it is necessary for the game to be continuous at infinity; this is true in games which, like this one, have overall payoffs that are a discounted sum of uniformly bound period payoffs. The main useful implication of this theorem is that we can take the future values of the choice variable as given. As Fudenberg and Tirole note, this is simply the principle of optimality of dynamic programming.

\subsection{Military Regime}

In this political regime the politician makes no decision and the general solves the following:

$$
V^{g}(G)=\max _{\tau \in\{0,1\}}\left\{\mu f(\tau) E+(1-\tau) \delta+\beta V^{g^{\prime}}(G)\right\}
$$

Using the one-stage deviation principle in the current period, the general must choose between setting $\tau=0$ and receiving $\delta$ in the current period, and setting $\tau=1$ and receiving $\mu \sigma E$ in the current period. The expected payoffs generated by these choices are:

$$
\begin{aligned}
& V^{g}(\widehat{\tau}(G)=0 ; G)=\delta+\beta V^{g \prime}(G) \\
& V^{g}(\widehat{\tau}(G)=1 ; G)=\mu \sigma E+\beta V^{g \prime}(G)
\end{aligned}
$$

Lemma 1 (Military Regime) If (i) $\delta \geq \mu \sigma E$, the general chooses $\widehat{\tau}(G)=0$ and his value is $V^{g}(G)=\frac{\delta}{1-\beta}$. If (ii) $\delta<\mu \sigma E$, he chooses $\widehat{\tau}(G)=1$ and his value is $V^{g}(G)=\frac{\mu \sigma E}{1-\beta}$.

Proof. See the Appendix.

This lemma shows that in a military regime the general's decision will depend on the value he places on policy. Case (i) shows that a general who places a large relative weight on policy will task the military with policy. If, as in case (ii), the general places a large relative weight on winning wars (because he does not care much for policy or because he is likely to win, war is 
likely, or winning wars produces a high payoff), he will task the military with defense. Since by assumption the general does not face the threat of a coup, his decisions are not affected by strategic considerations.

\subsection{Civilian Regime}

Suppose the politician is in office. A general will not stage a coup to try to overthrow her if the expected payoff from doing so is less than the expected payoff from staying in a civilian regime,

$$
f^{c}(\tau) V^{g \prime}(G) \leq V^{g^{\prime}}(P)
$$

This condition follows from (4) and involves the next period's value functions. The right hand side shows the expected value of doing nothing: in the next period the regime continues to be civilian. On the left hand side, the coup succeeds with probability $f^{c}(\tau)$, in which case the general becomes the incumbent in the next period and the regime switches to a military one. If a coup is staged and fails the general is removed at the end of the period.

Now suppose that in equilibrium coups do not take place in the current period if the regime is $P$, then from stationarity and the Markov assumption they also do not happen in the future if the regime is $P$. This implies that $V^{g \prime}(P)=V^{g \prime \prime}(P)$, and

$$
\begin{aligned}
V^{g \prime}(P) & =\mu f(\tau) E+(1-\tau) \delta+\beta V^{g^{\prime}}(P) \\
& =\frac{\mu f(\tau) E+(1-\tau) \delta}{1-\beta} .
\end{aligned}
$$

Then the constraint (6) becomes

$$
f^{c}(\tau) V^{g^{\prime}}(G) \leq \frac{\mu f(\tau) E+(1-\tau) \delta}{1-\beta}
$$

where the left hand side is the expected value of staging a coup, while the right hand side is the expected value when no coup is staged. 
If $\delta<\mu \sigma P$, we can rewrite the above as

$$
f^{c}(\tau)\left[\frac{\mu \sigma E}{1-\beta}\right] \leq f(\tau)\left[\frac{\mu E}{1-\beta}\right]+\frac{(1-\tau)}{1-\beta} \delta
$$

where we have made use of the results from the previous section. Notice that this expression always holds when $\tau=1$. If $\delta \geq \mu \sigma P$, the expression becomes

$$
f^{c}(\tau)\left[\frac{\delta}{1-\beta}\right] \leq f(\tau)\left[\frac{\mu P}{1-\beta}\right]+\frac{(1-\tau)}{1-\beta} \delta
$$

and coups are avoided for $\tau=1$ when

$$
\delta \leq \frac{\mu E}{\rho} \equiv \bar{\delta}
$$

A small $\delta$ makes coups relatively unappealing, even if they are likely to succeed. This expression is increasing in the probability of war $\mu$ : when war is likely, greater relative weight is placed on being prepared for it. Coups, which are aimed at tasking the general with policy, become relatively less appealing and will take place for a smaller range of parameter values.

To summarize:

Lemma 2 If $\delta>\bar{\delta}$, coups happen when $\tau=1$.

This lemma establishes that a military tasked with defense will stage a coup when the general places a sufficiently high weight on policy. When this is the case, the politician will have to take the possibility of a coup into account when deciding the military's task.

When the general places a low value on political control $(\delta \leq \bar{\delta})$, coups do not take place even if $\tau=1$. Recall that we can write

$$
V^{p}(\widehat{\tau}=1 ; P)=\max _{\tau \in\{0,1\}}\left\{\mu f(\tau) E+\gamma+\beta V^{p^{\prime}}(P)\right\}
$$

Using the one-stage-deviation principle, it follows that $\tau$ is chosen to maximize $\mu f(\tau) E+\gamma$, 
and so the politician clearly chooses $\widehat{\tau}(P)=1$. In short, it is optimal for the military to be tasked with defense and there are no coups in this case.

When the general values political control $(\delta>\bar{\delta})$, coups will happen if $\tau=1$. The politician's value function in this case is (from (2)):

$$
V^{p}(\widehat{\tau}=1 ; P)=\mu \sigma E+\gamma+\beta(1-\sigma \rho) V^{p \prime}(D) .
$$

The first two terms are the period 1 payoff, while the third is the expected continuation value. Using stationarity and the Markov assumption, it follows that

$$
V^{p}(\widehat{\tau}=1 ; P)=\frac{\mu \sigma E+\gamma}{1-\beta(1-\sigma \rho)} .
$$

If the politician sets $\tau=0$ instead, there are no coups and

$$
V^{p}(\widehat{\tau}=0 ; P)=\gamma+\beta V^{p \prime}(P)
$$

Using stationarity and the Markov assumption, it follows that

$$
V^{p}(\widehat{\tau}=0 ; P)=\frac{\gamma}{1-\beta}
$$

This helps show the decision faced by the politician: a value of $\widehat{\tau}=1$ implies a positive probability of winning wars, but it also has a negative impact on her likelihood of being in office in the next period. This is because it triggers a coup by increasing its probability of success. A simple comparison establishes that $\widehat{\tau}=0$ when

$$
\gamma>\frac{[1-\beta]}{\beta \rho} \mu E \equiv \bar{\gamma}
$$

and $\widehat{\tau}=1$ otherwise. In short, when the politician places a high value $\gamma$ on policy, she will task the general with policy to avoid coups and stay in power. When she values war, however, she 
will prefer to have the general tasked with defense, even if it results in her being removed from office. In this case the cost of avoiding coups, in the form of a reduced ability to fight wars, is too high.

We summarize these results in the following proposition:

Proposition 1 (Civilian Regime) Define $\bar{\gamma} \equiv \frac{[1-\beta]}{\beta \rho} \mu E$ and $\bar{\delta} \equiv \frac{\mu E}{\rho}$. (i) If $\delta \leq \bar{\delta}$ the politician chooses $\widehat{\tau}(P)=1$ and the general does not stage a coup $(\widehat{c}=0)$. (ii) If $\delta>\bar{\delta}$ and $\gamma \leq \bar{\gamma}$ the politician sets $\widehat{\tau}(P)=1$ and the general stages a coup $(\widehat{c}=1)$. (iii) If $\delta>\bar{\delta}$ and $\gamma>\bar{\gamma}$ the politician sets $\widehat{\tau}(P)=0$ and the general does not stage a coup $(\widehat{c}=0)$.

Part (i) of the proposition shows that when the general places a large relative value on winning wars ( $\delta$ small), the politician will task him with defense and he will not stage coups. Parts (ii) and (iii) show what happens when the general instead places a low relative value on winning wars ( $\delta$ high). In this case the general will stage a coup if he is tasked with defense. The politician must decide whether to task him with defense and face a coup or task him with policy and avoid the coup, at the cost of being unable to fight wars. She chooses the first option when war is relatively valuable ( $\gamma$ is low): she will be willing to face a coup in order to be prepared for war. She chooses the second option when war has a low relative value ( $\gamma$ is high). In this case she tasks the general with policy, making the military unable to fight wars or stage coups.

Proposition 1 allows us to classify civilian regimes according to the general's focus and whether he stages coups. A general who places a high value on war never stages coups, regardless of the task assigned; we refer to this as a No Control regime and it corresponds to region A in Figure 1. This case is consistent with what we observe in countries in North America and Western Europe, where the military is focused on defense, plays largely no role in politics, and stages no coups.

In region B of Figure 1 the general places a high relative weight on policy, while the politician places a relatively high value on war. The general stages coups, and we refer to these as Direct Control regimes. Here the politician is unwilling to make the concessions necessary to 


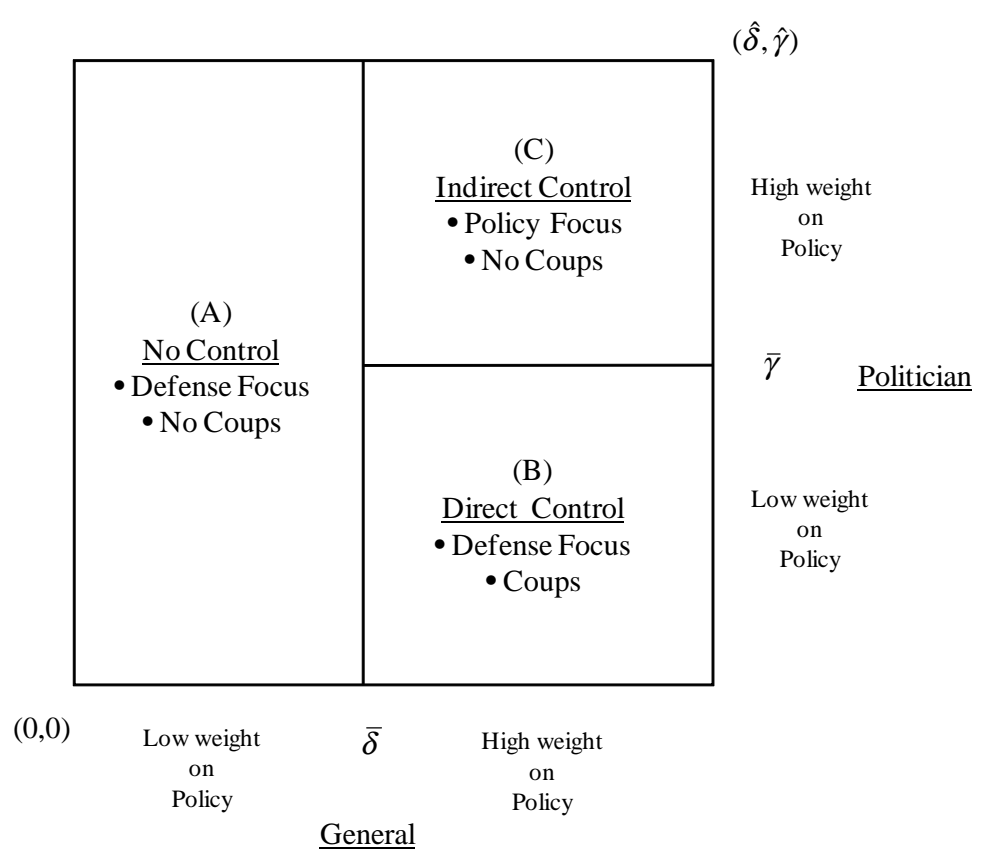

Figure 1: Military Focus and Coups

avoid coups. As a result, the general stages a coup in an attempt to establish direct control over policy. Chile's government under Allende is an example of such a regime: Allende needed a strong military in case of attack by both internal and foreign enemies. ${ }^{13}$

In region $\mathrm{C}$ the general is tasked with policy; this happens because both the general and the politician give a low value to war, and the politician can prevent coups by tasking the general with policy. We refer to this as an Indirect Control regime, and the majority of current Latin American democracies fall into this category.

In the next section we discuss the comparative statics with respect to the probability of war $\mu$, but we first establish two straightforward results:

Proposition 2 (Comparative Statics) (i) An increase in $\rho$ causes both $\bar{\delta}$ and $\bar{\gamma}$ to decrease. (ii) An increase in $E$ causes both $\bar{\delta}$ and $\bar{\gamma}$ to increase.

\footnotetext{
${ }^{13}$ Allende used the military in several instances to repress political opponents. Furthermore, Chile views a strong military as necessary because of the military threat posed by Bolivia and Peru (Nunn, 1976).
} 
Greater $\rho$ results in a higher probability of success for coups, so that the general is more likely to stage them and the cutoff value $\bar{\delta}$ decreases. It also makes the politician more interested in avoiding coups (since they are more likely to succeed), resulting in a decrease in the cutoff value $\bar{\gamma}$. An increase in $E$ makes being prepared for war more desirable to both the general, who is less interested in coups, and the politician, who is less interested in tasking the general with policy. As a result, both $\bar{\delta}$ and $\bar{\gamma}$ increase.

\section{War}

The likelihood of war plays a central role in our model. An increase in the probability of war $\mu$ makes war relatively more appealing for the general than policy, so that $\bar{\delta}$ increases. Likewise, it makes it more costly for the politician to try to avoid coups by tasking the general with policy, so $\bar{\gamma}$ also increases. In order to determine how these changes affect the likelihood of having a general focused on policy and the probability of a coup, we must determine how the changes in $\bar{\delta}$ and $\bar{\gamma}$ affect the parameter ranges for which the three types of civilian regimes arise in equilibrium. We begin with the following definition.

Definition Let $\widehat{\delta}, \widehat{\gamma} \leq E$ be two values such that $\delta \leq \widehat{\delta}$ and $\gamma \leq \widehat{\gamma}$. (i) The parameter range over which a No Control regime exists is defined as the area $\bar{\delta} \widehat{\gamma}$. (ii) The parameter range over which a Direct Control regime exists is defined as the area $(\widehat{\delta}-\bar{\delta})(\widehat{\gamma}-\bar{\gamma})$. (iii) The parameter range over which an Indirect Control regime exists is defined as the area $(\widehat{\delta}-\bar{\delta}) \bar{\gamma}$. These corresponds to areas $(A),(B)$ and $(C)$ in Figure 1.

We can now establish the following:

Proposition 3 (War) An increase in the likelihood of war $\mu$ : (i) increases the parameter range for which a country can have a military focused on defense that does not stage coups (region (A)), (ii) decreases the parameter range for which the military is tasked with policy to avoid coups 
(region (C)), (iii) has a non-monotonic effect on the parameter range for which the military is focused on defense and stages coups (region (B)).

Proof. See the Appendix.

The first part of this proposition establishes that wars increase the parameter range for which the military will be tasked with defense but it will not stage coups. The reason is that wars make coups relatively less appealing for the general. The second part of the proposition is intuitive: since an increase in the frequency of war reduces the relative value the general gives to policy, he is less likely to stage a coup. War also increases the cost to the politician of having the military focus on policy. Both effects operate in the same direction, and as a result war reduces the range of parameters for which the military is tasked with policy.

The third and most interesting part of the proposition establishes how the likelihood of coups changes with the probability of war. It shows that there is a non-monotonic relationship between the frequency of wars and coups, with coups being least frequent for low and high probabilities of war. This result depends on how the effect of war on the actions of the politician interacts with the effect war has on the general's actions. When war is unlikely, the general will want to stage coups. To avoid them, the politician will task him with policy. The cost of doing this is that it undermines the general's ability to fight wars; this cost is low because wars are infrequent. The result is that coups are unlikely. When war is frequent, the general does not wish to stage coups; focusing on policy is costly because it involves undermining his ability to fight wars. As a result, coups are unlikely, even when the politician tasks the general with defense. Coups are more likely at intermediate frequencies of war, when it is possible for the general to want to stage coups, but for the politician to find it too costly to have him focus on policy.

Proposition 3 allows us to reconcile two conflicting views of the impact of war on the military's role in politics. The first is associated with Harold Laswell $(1937,1941)$ and is known as the "garrison state" view. It suggests that war leads to a politically involved military, and is based on the observation that conflict increased the militarization of society in Japan and Ger- 
many in the 1930s and 1940s. The "institutional" view, often credited to Stanislav Andreski $(1968,1980)$, asserts that war causes the military to become focused on defense and reduces its involvement in politics. It is more recent and was developed to explain the success of the U.S. and the Soviet Union in keeping their militaries under civilian control. Our result that war decreases the general's control over policy is consistent with the institutional view. If instead we look at coups, the institutional view holds only when war is frequent. For low levels of conflict, however, our results are consistent with the garrison state view: an increase in the frequency of war results in more coups and the possibility of a transition to a military regime.

These results reflect an effect of war that is captured in the instantaneous utility functions: it increases congruence between the politician and the general. When war is likely, the common term (the expected value of war) is high, in which case both the politician and the general are likely to agree that $\tau=1$ is optimal. In this case there will be no coups, since there is no disagreement over the choice variable. When war is unlikely, a conflict of interest arises between the politician and the general. The idea that war brings about congruence is not new; for example, historian Kenneth Morgan writes that "on the eve of the world war, therefore, Britain seemed to present a classic picture of a civilized liberal democracy on the verge of dissolution, racked by tensions and strains with which its sanctions and institutions were unable to cope. And yet, as so often in the past, once the supreme crisis of war erupted, these elements of conflict subsided with remarkable speed. An underlying mood of united purpose gripped the nation" (Morgan, 1984; p.582-583).

\section{Endogenous War}

So far we have assumed that war is exogenous. In reality, a country may choose to start a war, and in this section we show that our results are robust to allowing for this. Suppose that when the country is not attacked, the incumbent can decide to start a war. ${ }^{14}$ Again, the probability that

\footnotetext{
${ }^{14}$ In terms of the timeline in Section 2, this happens between steps 3 and 4.
} 
a war is won is given by (1). However, we now assume that while a successful war generates a common ego-rent of $E$, a lost war generates an ego-cost of $D .{ }^{15}$ Furthermore, we assume that

$$
\sigma(E+D)-D>0
$$

so that the expected value of fighting a war is positive. ${ }^{16}$ Finally, we simplify the algebra by assuming that if a coup takes place the incumbent is removed from office at the start of the next period regardless of the coup's outcome. ${ }^{17}$

Let $a^{i}=1$ for $i \in\{p, g\}$ when an incumbent $i$ decides to start a war, and $a^{i}=0$ otherwise. We can write the new payoff functions for the politician as follows:

$V^{p}(P)=\max _{\tau \in\{0,1\}, a^{p} \in\{0,1\}}\left\{\begin{array}{c}\mu f(\tau)[E+D]-\mu D+(1-\mu) a^{p} f(\tau)[E+D]-(1-\mu) a^{p} D \\ +\gamma+\beta\left(1-c_{t}\right) V^{p \prime}(P)\end{array}\right\}$

$$
V^{p}(G)=\mu f(\tau)[E+D]-\mu D+(1-\mu) a^{g} f(\tau)[E+D]-(1-\mu) a^{g} D+\gamma+\beta V^{p \prime}(G)
$$

where these differ from those in the previous section in two respects. First, wars that are lost generate a cost of $D$, so that the expected value of fighting a war is $f(\tau) E+(1-f(\tau)) D=$ $f(\tau)[E+D]-D$. Second, wars can be started by the incumbent, so that we now have an extra component $(1-\mu) a^{p} f(\tau)[E+D]-(1-\mu) a^{p} D=(1-\mu) a^{p}[f(\tau)[E+D]-D]$ if the incumbent is a politician (and an analogous expression if he is a general).

The new payoff functions for the general are:

$$
V^{g}(P)=\mu f(\tau)[E+D]-\mu D+(1-\mu) a^{p} f(\tau)[E+D]-(1-\mu) a^{p} D+(1-\tau) \delta
$$

\footnotetext{
${ }^{15}$ We now need to assume that losing a war is costly; otherwise wars would happen in every period.

${ }^{16}$ This can be easily seen by rewriting the condition as $\sigma E-(1-\sigma) D>0$. At the end of the Section we discuss what happens when this condition does not hold.

${ }^{17}$ This assumption does not affect the results in any qualitative way.
} 


$$
\begin{gathered}
+\beta \max _{c_{t} \in\{0,1\}}\left[\left(1-c_{t}\right) V^{g^{\prime}}(P)+c_{t} f^{c}(\tau) V^{g^{\prime}}(G)\right] \\
V^{g}(G)=\max _{\tau \in\{0,1\}, a^{g} \in\{0,1\}}\left\{\begin{array}{c}
\mu f(\tau)[E+D]-\mu D+(1-\mu) a^{g} f(\tau)[E+D]-(1-\mu) a^{g} D \\
+(1-\tau) \delta+\beta V^{g \prime}(G)
\end{array}\right\}
\end{gathered}
$$

In a military regime, the general's decisions are as follows:

Proposition 4 (Endogenous War 1) Suppose the regime is military, and let $\bar{\delta} \equiv \sigma[E+D]-$ $(1-\mu) D$. (i) If $\delta<\bar{\delta}$, the general chooses $\widehat{\tau}=1, \widehat{a}^{g}=1$, and his payoff is given by $V^{g}(G)=\frac{\sigma[E+D]-D}{1-\beta}$. (ii) If $\delta \geq \bar{\delta}$, the general chooses $\widehat{\tau}=0, \widehat{a}^{g}=0$, and his payoff is given by $V^{g}(G)=\frac{\delta-\mu D}{1-\beta}$. (iii) $\bar{\delta}$ is increasing in $\mu$.

Proof. See the appendix.

This result shows that a general focused on defense will choose to start wars, while if he focuses on policy he will not. Part (iii) of the proposition shows that the cutoff increases with the probability of war. This implies that military regimes that are more likely to be attacked are more likely to prepare for war, which then leads them to attack others; this gives rise to a "spiral of violence."

In a civilian regime, we can establish the following result:

Proposition 5 (Endogenous War 2) Suppose the regime is civilian, and let $\overline{\bar{\delta}}=\frac{\sigma(E+D)-D}{\sigma \rho}+$ $\mu D, \overline{\bar{\gamma}}=\frac{1-\beta}{\beta}[\sigma(E+D)-D]+\frac{\mu D}{\beta}$. Then (i) if $\delta<\overline{\bar{\delta}}$, the politician sets $\widehat{\tau}=1, \widehat{a}^{p}=1$ and the general does not stage a coup. (ii) If $\delta \geq \overline{\bar{\delta}}$ and $\gamma<\overline{\bar{\gamma}}$, the politician sets $\widehat{\tau}=1, \widehat{a}^{p}=1$ and the general stages a coup. (iii) If $\delta \geq \overline{\bar{\delta}}$ and $\gamma \geq \overline{\bar{\gamma}}$, the politician sets $\widehat{\tau}=\overline{\bar{e}}, \widehat{a}^{p}=0$ and the general does not stage a coup.

Proof. See the appendix.

This result is very similar to that without endogenous wars. The reason is that the choice of military focus again impacts on whether the politician starts a war, and this generates a "spiral of 
violence." More generally, the countries that are more likely to be attacked are also more likely to start a war, as the following Proposition shows:

Proposition 6 An increase in the likelihood of war increases the probability that a civilian regime starts a war in times of peace.

Proof. See the appendix.

Finally, we should note that relaxing assumption (11) causes wars to be costly in expectation, so that both the politician and the general agree that $a^{i}=0$ is always optimal. The problem then simplifies to that discussed in the previous section.

\section{Empirical Evidence: Wars and Coups}

In this section we show empirical evidence that is consistent with the model's prediction of a non-monotonic relationship between the likelihood of wars and coups, finding a robust nonmonotonic relationship between these variables.

We begin by estimating the cross-country specification:

$$
\operatorname{coup}_{i}=\alpha+\gamma_{1} \times \text { war }_{i}+\gamma_{2} \times \text { war }_{i}^{2}+\beta_{1} \times \text { controls }_{i}+\varepsilon_{i}
$$

where $\operatorname{coup}_{i}$ and war $_{i}$ measure the fraction of years in which coups or wars took place in country $i$, and serve as proxies for the probability of a coup and war. The quadratic term is a simple way of capturing the non-monotonicity predicted by the model. The controls $s_{i}$ will account for GDP and population in two ways: first, by using the World Bank's country income groups as dummies, and then by using the log of a country's GDP (in millions) and the log of population (in millions) in the year before it enters the sample (1964 or the year of independence). Finally, $\varepsilon_{i}$ is the error term. We also estimate a second specification:

$$
\operatorname{coup}_{i}=\alpha+\gamma_{1} \times \text { war }_{i}+\gamma_{2} \times I \times \text { war }_{i}+\beta_{1} \times \text { controls }_{i}+\varepsilon_{i}
$$


where $I=1$ if war $_{i}>0.5$ and 0 otherwise. This is another simple way of capturing the non-monotonicity predicted by the theoretical model.

One disadvantage of aggregating our data into a cross-country dataset is that the results will capture country specific time-invariant factors that can impact on both the frequency of wars and coups, but are difficult to measure or control for (e.g. institutions). One solution is to exploit the time dimension in the data, which allows us to introduce country fixed effects and exploit the within country variation over time. This requires that we define our variables differently, but the specifications are quite similar:

$$
\begin{aligned}
\operatorname{coup}_{i, t}= & \alpha+\gamma_{1} \times \text { war }_{i, t}+\gamma_{2} \times \text { war }_{i, t}^{2}+\beta_{1} \times \text { controls }_{i, t} \\
& +\lambda_{t}+\alpha_{i}+\varepsilon_{i, t}
\end{aligned}
$$

and

$$
\begin{aligned}
\operatorname{coup}_{i, t}= & \alpha+\gamma_{1} \times \text { war }_{i, t}+\gamma_{2} \times I \times \text { war }_{i, t}+\beta_{1} \times \text { controls }_{i, t} \\
& +\lambda_{t}+\alpha_{i}+\varepsilon_{i, t}
\end{aligned}
$$

where $\operatorname{coup}_{i, t}$ and war $_{i, t}$ now measure the fraction of years in country $i$ and period $t$ in which coups or wars took place, and control $i, t$ is measured in the year before the period starts. The periods are defined to be 5 years long: 1965-69, 1970-74, 1975-79, 1980-84, 1985-89, 1990-94, 1995-99. The $\lambda_{t}$ are period fixed effects, while the $\alpha_{i}$ are country fixed effects. The last term is a country and period specific error.

\subsection{The Data}

We use the PRIO/Uppsala Armed Conflict dataset, version 4 (Gleditsch et al., 2002; PRIO, 2006) to determine the years in which a country was at war. We include all years in which the country is listed as fighting in a conflict, with the exception of those in which both the enemy is listed 
as a "military faction" and the country experienced a coup. This means that we include both international and civil wars; the reasons for treating both types of war equally is that our model focuses on the interaction between politicians and generals, and in both cases their interests will be aligned. For example, it is clear that Colombia's civil war has brought the government and the military closer together. Our sample period is $1965-1999$, which are the years for which the coup data is available.

The data on coups comes primarily from the dataset compiled by Belkin and Schofer (2003), with some additional data from A.S. Banks' (2001) cross-national time-series data archive. The Belkin-Schofer (2003) coup database is the most accurate available. One of its main advantages is that it includes both successful and failed coups, and thus avoids the sample selection issues of widely used datasets that report only successful coups. To compile their data, Belkin and Schofer (2003) combined the list of coups available from a number of academic articles with that from Keesing's Contemporary Archives. They ensured its accuracy by consulting regional experts and checking conflicting cases with the New York Times and the Foreign Broadcast Information Service. More details can be found in their paper.

Tables 1 and 2 summarize the data. Table 1 shows the number of country-years in which wars were fought and coups took place: of a total of 4,440 country-years, coups took place in only 203 and wars in 837. Clearly both events are uncommon. Furthermore, since our model's prediction applies only to non-military regimes, we only consider country-years in which the head of state is not a military officer. To find these cases we use the variable $S 21 F 3$ from A.S. Banks (2001), which codes the identity of the head of state: it takes a value of 1 if the head of state is a monarch, 2 if it is a president, 3 if it is a military officer, and 4 if other (including a theocratic ruler). We drop all 257 observations coded as a 3, but this has no relevant impact on the results we present below. ${ }^{18}$

Table 2 shows the frequency of wars and coups. The first part focuses on the cross-country variables, where the frequency of war is measured as the fraction of years in which the country

\footnotetext{
${ }^{18}$ We should clarify that our data includes many dictatorship in which the head of state is a civilian and not a military officer.
} 
was at war, while the frequency of coups refers to the fraction of years in which a coup took place. As before, wars are more frequent than coups, with some countries being at war in every year they appear in the sample. The second part of the table shows the frequencies calculated over 5 year intervals: again wars are more frequent than coups.

The controls for income and population are taken from the World Bank's World Development Indicators (2007).

\subsection{Results}

Table 3 reports the results for the cross-country specifications (12) and (13). The first column shows a quadratic relationship between wars and coups, as predicted by the model. The maximum occurs at a frequency of 0.47 , so countries that experienced war for about half the years have the highest likelihood of experiencing coups (although most of the countries are to the left of the maximum). The second column in Table 2 shows that this relationship remains after we introduce the World Bank country income dummies, a rough measure of wealth. Finally, the third column shows the results when we control for GDP and population measured in the year before the country enters the sample. In all cases the signs are as predicted by the theoretical model, and the coefficients are significant. The second part of Table 3 reports the results for specification (13); in this case the coefficients are about half the size and largely insignificant. However, the signs remain the same, showing that the non-monotonic relationship also arises in this case.

As we discussed above, it is possible that there are country specific features that are driving all of these variables; for example, institutions may affect the frequency of both wars and coups. To partially address these issues we focus on specifications (14) and (15); Table 4 shows the results. In the first column we report the results for a pooled regression, where once again war exhibits a significant quadratic relationship with coups. In the second column we control for country and time fixed effects, and the results lose some significance. The coefficients are similar to those in the cross-country regressions and the signs are as expected. In column 3 we 
control for income and population; the signs on war remain the same, but the standard errors are larger and significance largely disappears. Specification (15), on the other hand, shows the expected pattern of signs and they are significant. The coefficients are very similar to those in specification (14).

These tests suggest that there is a consistent non-monotonic relationship between wars and coups. Although significance may depend on the specification used, the signs remain the same across all the specifications. The fact that the results do not change in any substantial way across specifications should reassure us that the quadratic relationship between wars and coups is robust.

\section{Conclusion}

In this paper we develop a theory of the military's role in policy-making, and consider when it intervenes in politics and whether its involvement is direct or indirect. We argue that the military's role in fighting wars must be taken into account when thinking about this organization's political actions. We show that both roles have different costs and benefits to the military, which vary with the likelihood of war. War makes indirect involvement less likely, but first increases and then decreases the probability of direct involvement. This is because war makes successful coups easier to stage, but reduces their payoff. This result implies a non-monotonic relationship between the likelihood of war and coups in non-military regimes, and we present empirical evidence consistent with this prediction.

At the beginning of this paper we argued that it was important to understand the role played by the military in the policy-making process, and that this likely had an impact on economic outcomes. In this paper we have addressed the first point, but said nothing about the second. This very important question merits its own independent treatment, and so we leave it for future work. We should note, however, that there is a growing literature that looks at how democracies and non-democracies differ in their economic policies and outcomes; it includes Gil, Mulligan and 
Sala-i-Martin (2004), who compare the policies chosen by democracies and non-democracies, and Besley and Kudamatsu (2008), who consider which types of non-democracies choose better policies. Future work should look in more detail at how policy choices differ depending on the degree of military involved in politics. 


\section{References}

[1] Acemoglu, Daron and James Robinson (2001), "A Theory of Political Transitions," The American Economic Review 91, 938-963.

[2] Acemoglu, Daron, Simon Johnson, and James Robinson (2001), "The Colonial Origins of Comparative Development: An Empirical Investigation," The American Economic Review 91, 1369-1401.

[3] Acemoglu, Daron and James Robinson (2005), Economic Origins of Dictatorship and Democracy, Cambridge University Press.

[4] Acemoglu, Daron, Davide Ticchi and Andrea Vindigni (2009), "A Theory of Military Dictatorships," unpublished typescript.

[5] Andreski, Stanislaw (1968), Military Organization and Society, University of California Press.

[6] Andreski, Stanislaw (1980), "On the Peaceful Disposition of Military Dictatorships," Journal of Strategic Studies 3, 3-10.

[7] Banks, A.S. (2001), Cross-national time-series data archive (data set), Binghamton, NY: Computer Systems Unlimited.

[8] Belkin, Aaron and Evan Schofer (2003), "Toward a Structural Understanding of Coup Risk," The Journal of Conflict Resolution 47, 594-620.

[9] Besley, Timothy and Masayuki Kudamatsu (2008), "Making Autocracy Work," in Elhanan Helpman (ed.) Institutions and Economic Performance, Harvard University Press.

[10] Besley, Timothy and Torsten Persson (2008a), "The Origins of State Capacity: Property Rights, Taxation and Politics," forthcoming in the American Economic Review. 
[11] Besley, Timothy and Torsten Persson (2008b), "Wars and State Capacity," forthcoming in the Journal of the European Economic Association.

[12] Besley, Timothy and Torsten Persson (2008c), "The Incidence of Civil War: Theory and Evidence," NBER Working Paper 14585.

[13] Besley, Timothy and Torsten Persson (2009), "Repression or Civil War?", forthcoming in American Economic Review, Papers and Proceedings.

[14] Besley, Timothy and James Robinson (2007), "A Theory of Military Politics," work in progress.

[15] Chassang, Sylvain and Gerard Padro-i-Miquel (2008), "Conflict and Deterrence under Strategic Risk," unpublished typescript.

[16] Collier, Paul and Anke Hoeffler (2007), "Military Spending and the Risks of Coups d'Etat," unpublished typescript.

[17] Desch, Michael C. (1999), Civilian Controls of the Military, The Johns Hopkins University Press.

[18] Feaver, Peter (2003), Armed Servants, Harvard University Press.

[19] Finer, Samuel E. (1962), The Man on Horseback, Pall Mall Press.

[20] Fudenberg, Drew and Jean Tirole (1991), Game Theory, The MIT Press.

[21] Gil, Ricard, Casey B. Mulligan and Xavier Sala-i-Martin (2004), "Do Democracies have Different Public Policies than Non-Democracies?," Journal of Economic Perspectives 18, pp. 51-74.

[22] Gleditsch, Nils P., Peter Wallensteen, Mikael Eriksson, Margareta Sollenbert \& Havard Strand (2002), "Armed Conflict 1946-2001: A New Dataset," Journal of Peace Research 39(5): 615-637. 
[23] Howard, Michael (1976), War in European History, The Oxford University Press.

[24] Huntington, Samuel P. (1957), The Soldier and the State, Harvard University Press.

[25] Jackson, Matthew and Massimo Morelli (2008), "Strategic Militarization, Deterrence and Wars," typescript.

[26] Laswell, Harold D. (1937), "Sino-Japanese Crisis: The Garrison State versus the Civilian State," China Quarterly 649.

[27] Laswell, Harold D. (1941), "The Garrison State," American Journal of Sociology 46, 455468.

[28] Leon, Gabriel (2006). "The Military, Wealth and Strategic Redistribution," unpublished typescript.

[29] Leon, Gabriel (2007). "Loyalty for Sale? The Military and Economic Incentives," unpublished typescript.

[30] Londregan, John and Keith Poole (1990), "Poverty, The Coup Trap, and the Seizure of Executive Power," World Politics 42, 151-183.

[31] Morgan, Kenneth O. (1984), "The Twentieth Century," The Oxford History of Britain, Oxford University Press.

[32] Nordlinger, Eric A. (1977), Soldiers in Politics, Prentice Hall.

[33] North, Douglass C. (1981), Structure and Change in Economic History, New York: W.W. Norton \& Co.

[34] North, Douglass C. and Robert P. Thomas (1973), The Rise of the Western World: A New Economic History, Cambridge: Cambridge University Press.

[35] Nunn, Frederick M. (1976), The Military in Chilean History, University of New Mexico Press. 
[36] Persson, Torsten and Guido Tabellini (2003), The Economic Effects of Constitutions, Cambridge, MA: MIT Press.

[37] PRIO (2006), Armed Conflict Data Version 4-2006b. Available at http://new.prio/no?CSCW-Datasets/Data-on-Armed-Conflict/UppsalaPRIO-ArmedConflicts-Dataset/.

[38] Tilly, Charles (1990), Coercion, Capital and European States, AD 990-1992, Blackwells.

[39] World Bank (2007), World Development Indicators, Washington DC, World Bank, data file. 


\section{A Appendix: Proofs}

\section{Lemma 1}

Proof. It follows from stationarity and the Markov assumption that if the general chooses $\tau=0$ in the current period, he does so in all future periods; likewise if he sets $\tau=1$. This implies that $V^{i}(r)=V^{i \prime}(r)$, which allows us to solve for $V^{g}(G)$ when $\widehat{\tau}(G)=0$ and when $\widehat{\tau}(G)=1$. Comparing these two values produces the condition $\delta \gtreqless \mu \sigma P$.

\section{Proposition 3}

Proof. To prove (i) notice that the range $\bar{\delta} \widehat{\gamma}$ is increasing in the probability of war $\mu$. For part (ii) the relevant range is $(\widehat{\delta}-\bar{\delta})(\widehat{\gamma}-\bar{\gamma})$, which becomes smaller with $\mu$. Finally, the range for part (iii) is given by $(\widehat{\delta}-\bar{\delta}) \bar{\gamma}$, which has a derivative with respect to $\mu$ equal to $\frac{-E}{\rho} \frac{(1-\beta)}{\beta \rho} \mu E+\left[\widehat{\delta}-\frac{\mu E}{\rho}\right] \frac{(1-\beta)}{\beta \rho} E$, which equals $\widehat{\delta} \frac{(1-\beta)}{\beta \rho} E>0$ when evaluated at $\mu=0$ and $\frac{-2 E}{\rho} \frac{(1-\beta)}{\beta \rho} E+\widehat{\delta} \frac{(1-\beta)}{\beta \rho} E<0$ at $\mu=1$, because $\widehat{\delta}<E$.

\section{Proposition 4}

Proof. Suppose the general chooses not to start a war so that $a^{g}=0$. His payoff is given by $\mu f(\tau)[E+D]-\mu D+(1-\tau) \delta+\beta V^{g \prime}(G)$, and he will choose either $\tau=1$ or $\tau=0$. If he chooses the former, his payoff is $\frac{\mu \sigma[E+D]-\mu D}{1-\beta}$; if he chooses the latter, his payoff is equal to $\frac{\delta-\mu D}{1-\beta}$. It then follows that if $\delta<\mu \sigma[E+D]$ the general chooses (i) $a^{g}=0, \tau=1$, and his payoff is $\frac{\mu \sigma[E+D]-\mu D}{1-\beta}$; if $\delta \geq \mu \sigma[E+D]$ he chooses (ii) $a^{g}=0, \tau=0$, and his payoff is given by $\frac{\delta-\mu D}{1-\beta}$.

If instead he chooses $a^{g}=1$, his payoff becomes $f(\tau)[E+D]-D+(1-\tau) \delta+\beta V^{g \prime}(G)$, where again the choice is between $\tau=0$ and $\tau=1$. If he chooses (iii) $a^{g}=1, \tau=1$, then his 
payoff is $\frac{\sigma[E+D]-D}{1-\beta}$, and if he chooses (iv) $a^{g}=1, \tau=0$, then it is $\frac{\delta-D}{1-\beta}$. It is straightforward to see that assumption (11) ensures that the payoff under (iii) is always greater than that under (i), and that (ii) is always greater than (iv). It follows that the choice is between (ii) and (iii), and (ii) delivers a greater payoff whenever

$$
\frac{\delta-\mu D}{1-\beta}>\frac{\sigma[E+D]-D}{1-\beta}
$$

or equivalently, when

$$
\delta>\sigma[E+D]-(1-\mu) D \equiv \bar{\delta} .
$$

This proves parts (i) and (ii). Part (iii) follows from differentiating $\bar{\delta}$ with respect to $\mu$.

\section{Proposition 5}

Proof. In a civilian regime, the general will stage a coup if $f^{c}(\tau) V^{g^{\prime}}(G) \leq V^{g^{\prime}}(P)$.

Part A: Suppose that $\tau=1$ and $\delta<\bar{\delta}$.

From the previous proposition $V^{g \prime}(G)=\frac{\sigma[E+D]-D}{1-\beta}$. The no coup condition becomes

$$
\sigma \rho \frac{\sigma[E+D]-D}{1-\beta} \leq \frac{\mu \sigma[E+D]-\mu D+(1-\mu) a^{p} \sigma[E+D]-(1-\mu) a^{p} D}{1-\beta} .
$$

If $a^{p}=1$ the condition becomes $\sigma \rho[\sigma[E+D]-D] \leq \sigma[E+D]-D$, so that it is always satisfied, giving the politician a payoff of

$$
\frac{\sigma[E+D]-D+\gamma}{1-\beta}
$$

If $a^{p}=0$, the highest payoff is when coups do not take place, in which case the politician receives

$$
\frac{\mu \sigma[E+D]-\mu D+\gamma}{1-\beta}
$$

but this is lower than the payoff from $a^{p}=1$. To summarize: when $\delta<\bar{\delta}$, the politician sets 
$\tau=1$ and (11) holds, it is optimal for the politician to set $a^{p}=1$ and there are no coups.

Part B: Suppose that $\tau=1$ and $\delta \geq \bar{\delta}$.

Then from the previous proposition $V^{g \prime}(G)=\frac{\delta-\mu D}{1-\beta}$. If the politician sets $a^{p}=1$, coups will be avoided if

$$
\sigma \rho \frac{\delta-\mu D}{1-\beta} \leq \frac{\sigma(E+D)-D}{1-\beta}
$$

or equivalently,

$$
\delta \leq \frac{\sigma(E+D)-D}{\sigma \rho}+\mu D \equiv \overline{\bar{\delta}}
$$

If the politician sets $a^{p}=0$, coups are avoided when

$$
\sigma \rho \frac{\delta-\mu D}{1-\beta} \leq \mu \frac{\sigma(E+D)-D}{1-\beta}
$$

or equivalently,

$$
\delta \leq \mu \frac{\sigma(E+D)-D}{\sigma \rho}+\mu D \equiv \widetilde{\delta}
$$

where $\widetilde{\delta} \leq \overline{\bar{\delta}}$. We need to consider three regions. First (i) $\bar{\delta} \leq \delta \leq \widetilde{\delta}$, in which case coups are avoided regardless of whether $a^{p}=0$ or $a^{p}=1$. Since the payoff for the first choice is

$$
\frac{\mu \sigma(E+D)-\mu D+\gamma}{1-\beta}
$$

while for the latter it is

$$
\frac{\sigma(E+D)-D+\gamma}{1-\beta}
$$

using assumption (11) it follows that the latter is greater, so the politician will choose $a^{p}=1$.

Now suppose that (ii) $\widetilde{\delta}<\delta \leq \overline{\bar{\delta}}$, where coups are avoided only if $a^{p}=1$. If the politician sets $a^{p}=0$, her payoff is

$$
\mu \sigma(E+D)-\mu D+\gamma
$$


while her payoff if she sets $a^{p}=1$ is

$$
\frac{\sigma(E+D)-D+\gamma}{1-\beta}
$$

Again the politician chooses $a^{p}=1$ and there are no coups.

Now suppose that (iii) $\delta \geq \overline{\bar{\delta}}$. In this case coups take place regardless of the value of $a^{p}$. If the politicians chooses $a^{p}=0$ her payoff is

$$
\mu \sigma(E+D)-\mu D+\gamma
$$

and if she chooses $a^{p}=1$ her payoff is

$$
\sigma(E+D)-D+\gamma
$$

where given assumption (11) she clearly always prefers the latter.

To summarize, Parts A and B show that when $\tau=1$ the politician sets $a^{p}=1$. If $\delta<\overline{\bar{\delta}}$ coups are avoided and her payoff is

$$
\frac{\sigma(E+D)-D+\gamma}{1-\beta}
$$

while if $\delta \geq \overline{\bar{\delta}}$ coups take place and her payoff is

$$
\sigma(E+D)-D+\gamma
$$

Part C: We now check when it is optimal for the politician to choose $\tau=1$. Suppose the politician sets $\tau=0$. In this case coups never take place, and the politician receives a payoff of

$$
\frac{-\mu D-(1-\mu) a^{p} D+\gamma}{1-\beta}
$$


in which case she clearly sets $a^{p}=0$ and receives

$$
\frac{-\mu D+\gamma}{1-\beta}
$$

When $\delta<\overline{\bar{\delta}}$ the politician will choose $\tau=1, a^{p}=1$ and no coups over $\tau=0, a^{p}=0$ and no coups when

$$
\frac{\sigma(E+D)-D+\gamma}{1-\beta}>\frac{-\mu D+\gamma}{1-\beta}
$$

which always holds because of Assumption (11).

When $\delta \geq \overline{\bar{\delta}}$ the politician will choose $\tau=1, a^{p}=1$ and coups over $\tau=0, a^{p}=0$ and no coups when

$$
\sigma(E+D)-D+\gamma>\frac{-\mu D+\gamma}{1-\beta}
$$

which holds whenever

$$
\gamma<\frac{1-\beta}{\beta}[\sigma(E+D)-D]+\frac{\mu D}{\beta} \equiv \overline{\bar{\gamma}}
$$

This establishes the result.

\section{Proposition 6}

Proof. The expressions $\overline{\bar{\delta}}$ and $\overline{\bar{\gamma}}$ are both increasing in $\mu$, so a greater $\mu$ enlarges the parameter space for which the politician chooses $\widehat{\tau}=1$ and $\widehat{a}^{p}=1$. 
Table 1: Coups, Wars and Heads of State (1965-1999)

\begin{tabular}{|c|c|}
\hline & $\begin{array}{c}\text { Number of } \\
\text { Country-Years }\end{array}$ \\
\hline \multicolumn{2}{|l|}{ Coups } \\
\hline Coups & 203 \\
\hline No Coups & 4,237 \\
\hline \multicolumn{2}{|l|}{$\underline{\text { Wars }}$} \\
\hline Wars & 837 \\
\hline No Wars & 3,603 \\
\hline \multicolumn{2}{|c|}{ Head of State } \\
\hline Military Officer & 257 \\
\hline \multirow[t]{2}{*}{ Other } & 4,183 \\
\hline & 4,440 \\
\hline
\end{tabular}

The values refer to the number of country-years in which there was at least one coup or one war. The identity of the head of state is from the Banks (2001) dataset variable S21F3, where a military head of state is coded as a ' 3 '. 
Table 2: Frequency of Coups and Wars (1965-1999)

\begin{tabular}{|c|c|c|c|c|c|c|}
\hline & Median & Mean & $\begin{array}{l}\text { Standard } \\
\text { Deviation }\end{array}$ & Max & Min & Observations \\
\hline \multicolumn{7}{|l|}{ Frequencies } \\
\hline \multicolumn{7}{|l|}{ Cross-Country } \\
\hline$\overline{\text { Coups }}$ & 0 & 0.031 & 0.052 & 0.25 & 0 & 150 \\
\hline Wars & 0.03 & 0.19 & 0.273 & 1 & 0 & 150 \\
\hline \multicolumn{7}{|l|}{$\frac{\text { Panel }}{\text { (5-year periods })}$} \\
\hline Coups & 0 & 0.035 & 0.113 & 1 & 0 & 881 \\
\hline Wars & 0 & 0.19 & 0.344 & 1 & 0 & 881 \\
\hline
\end{tabular}

The frequency of coups is measured as the fraction of years in which the country experience at least a coup. The frequency of war is measured as the fraction of years in which the country was involved in at least one armed conflict (excluding coups). 
Table 3: Wars and Coups, Cross-Country

\begin{tabular}{|c|c|c|c|c|c|c|}
\hline & (1) & (2) & (3) & (4) & (5) & (6) \\
\hline & Coups & Coups & Coups & Coups & Coups & Coups \\
\hline & \multicolumn{3}{|c|}{ Specification 12} & \multicolumn{3}{|c|}{ Specification 13} \\
\hline Wars & $\begin{array}{c}0.202^{* * * *} \\
(0.055)\end{array}$ & $\begin{array}{c}0.163 * * * \\
(0.056)\end{array}$ & $\begin{array}{c}0.185^{* *} \\
(0.073)\end{array}$ & & & \\
\hline Wars $^{2}$ & $\begin{array}{c}-0.214 * * * \\
(0.059)\end{array}$ & $\begin{array}{c}-0.176 * * * \\
(0.062)\end{array}$ & $\begin{array}{c}-0.193 * * \\
(0.078)\end{array}$ & & & \\
\hline Wars $(>=0.5)$ & & & & $\begin{array}{c}0.103 * * \\
(0.048)\end{array}$ & $\begin{array}{c}0.079 \\
(0.050)\end{array}$ & $\begin{array}{l}0.100^{*} \\
(0.059)\end{array}$ \\
\hline Wars $(<0.5)$ & & & & $\begin{array}{l}-0.079 \\
(0.049)\end{array}$ & $\begin{array}{c}-0.063 \\
(0.050)\end{array}$ & $\begin{array}{l}-0.080 \\
(0.057)\end{array}$ \\
\hline Income & & & $\begin{array}{c}-0.010 * * * \\
(0.003)\end{array}$ & & & $\begin{array}{c}-0.011 * * * \\
(0.003)\end{array}$ \\
\hline Population & & & $\begin{array}{c}0.003 \\
(0.004)\end{array}$ & & & $\begin{array}{c}0.006 \\
(0.004)\end{array}$ \\
\hline WB Income group & NO & YES & NO & NO & YES & NO \\
\hline Observations & 150 & 148 & 115 & 150 & 148 & 115 \\
\hline R-squared & .1182 & .1750 & .1997 & .064 & .14 & .14 \\
\hline
\end{tabular}


Table 4: Wars and Coups, Panel

\begin{tabular}{|c|c|c|c|c|c|c|}
\hline & (1) & (2) & (3) & (4) & $\overline{(5)}$ & (6) \\
\hline & Coups & Coups & Coups & Coups & Coups & Coups \\
\hline & \multicolumn{3}{|c|}{ Specification 14} & \multicolumn{3}{|c|}{ Specification 15} \\
\hline Wars & $\begin{array}{c}0.190^{* * * *} \\
(0.049)\end{array}$ & $\begin{array}{c}0.207 * * \\
(0.094)\end{array}$ & $\begin{array}{l}0.189^{*} \\
(0.108)\end{array}$ & & & \\
\hline Wars $^{2}$ & $\begin{array}{c}-0.155^{* * * *} \\
(0.051)\end{array}$ & $\begin{array}{l}-0.134 \\
(0.102)\end{array}$ & $\begin{array}{l}-0.094 \\
(0.114)\end{array}$ & & & \\
\hline Wars $(>=0.5)$ & & & & $\begin{array}{c}0.210^{* * *} \\
(0.038)\end{array}$ & $\begin{array}{c}0.254 * * * \\
(0.083)\end{array}$ & $\begin{array}{c}0.262 * * * \\
(0.100)\end{array}$ \\
\hline Wars $(<0.5)$ & & & & $\begin{array}{c}-0.171 * * * \\
(0.038)\end{array}$ & $\begin{array}{c}-0.179 * * \\
(0.087)\end{array}$ & $\begin{array}{l}-0.167 \\
(0.101)\end{array}$ \\
\hline Income & & & $\begin{array}{l}-0.011 \\
(0.019)\end{array}$ & & & $\begin{array}{l}-0.003 \\
(0.020)\end{array}$ \\
\hline Population & & & $\begin{array}{l}-0.031 \\
(0.036)\end{array}$ & & & $\begin{array}{l}-0.033 \\
(0.035)\end{array}$ \\
\hline $\begin{array}{l}\text { Country and Year } \\
\text { Fixed Effects }\end{array}$ & NO & YES & YES & NO & YES & YES \\
\hline Observations & 881 & 881 & 723 & 881 & 881 & 723 \\
\hline R-squared & .030 & .283 & .281 & .042 & .296 & .294 \\
\hline
\end{tabular}

